DOI: https://doi.org/10.14311/TPFM.2022.020

\title{
EXPERIMENTAL ANALYSIS OF TREATMENT PERFORMANCE BY OPTIMIZATION OF EFFECTIVE PARAMETERS ON CORRUGATED PLATES USED IN TREATMENT SYSTEMS
}

\author{
Mehmet Oruç, Sedat Yayla \\ Van Yuzuncu Yil University, Mechanical Engineering Department 65100, Tuşba, Van,
}

\begin{abstract}
Crude oil, which is brought to the surface from underground with high cost and loss of time, contains water, gas and some solids. The most widely used method for separating the crude oil brought to the earth from water is the separation method, which is one of the gravitational separation methods, using corrugated plates.In this study, 3 different $\mathrm{Re}$ numbers $(3033.058,4766.2345,6499.411)$ of 1 st Processed crude oil sample, the ratio of 3 different hole diameters of the corrugated plates to the plate width $(0.018,0.021,0.024)$ and 3 different mounting angles $(0,25,50$ degrees) parameters were taken into consideration and the effect of the relevant parameters on the separation efficiency was investigated.In order to reduce the number of experiments and save on cost and experiment time, without affecting the probability of finding the highest value of the separation efficiency, the Response Surface Method (RSM) was optimized with the Box-Behnken method and relevant trial designs were created.In line with these experimental designs, the relevant experiments were carried out in duplicate.
\end{abstract}

Keywords: oil-water separation, response surface methodology, box-behnken desing, corrugated plates

\section{Introduction}

Crude oil has been unearthed since the 18th century; It is produced as a mixture of water, crude oil and some gas. In order to separate the other components produced with crude oil, treatment plants are built and new methods are being developed every day in the relevant field. In the past, fluids were transferred to the separation tank to separate oil and gas, and water was passed through the treatment plant throughout the entire process to further separate the remaining water [1-2]. The water produced and brought to the surface is polluted because it contains gas and crude oil, so it cannot be used for drinking and irrigation. Studies have been conducted on the impact of the use of water produced in large quantities during the extraction of oil or gas to the surface on the life cycle and the ecological damage it causes to nature [3]. Statistics of the operational characteristics of the production area were obtained and compiled, and the factors affecting the ecological life cycle over a period of more than 15 years were evaluated. In the oil production industry, the water produced constitutes the largest portion of the waste fluids. The ratio of water to oil is approximately 3:1. [4-6]. It occurs as a result of the production of oil and gas from underground reservoirs [7-8]. It is evaluated that the water produced in the world is around 200 million barrels/day on average [9]. The water extracted during the oil production process increases sensationally and this increase does not remain constant throughout oil production. This supports a negative correlation between water and oil production[10-13]. In areas where production has been made for a long time, the water rate can be more than $90 \%$ [14]. With globalization, an increase in the amount of water production is expected in recent days and it is stated that the presence of this water in the ecosystem will be a serious concern [15]. There are various methods for separating oil from the produced water. Gravitational separation has been used for a long time. This system, which has been advocated by various studies, describes all suitable phase separation techniques that involve the separation of materials of different densities by gravity. Gravity techniques have wide and varied applications for separating water produced in oil production. The gravity system is economically beneficial, and gravity is the most widely used technique for oil separation in the petroleum industry [16-18].

Within the scope of this study, 3 different Re numbers $(3033.058,4766.2345,6499.411)$ of the 1 st Processed crude oil sample obtained from Batman Batı Raman facility, the ratio of 3 different hole diameters of the corrugated plates to the plate width $(0.018,0.021,0.024)$ and the separation system of the corrugated plates. 3 different mounting angles $(0,25,50$ degrees $)$ parameters are discussed. In line with 
these parameters, relevant experimental setups were set up and necessary studies were carried out. Since there are 3 different parameters and 3 different levels of each parameter, the number of experiments to be done for all possibilities is quite high. Without affecting the probability of finding the highest value of the separation efficiency, in order to reduce the number of experiments and save cost and experiment time, the Response Surface Method (RSM) was optimized with the Box-Behnken method and relevant trial designs were created. Related experiments were carried out in line with these experimental designs.

\section{Material and Method}

The relationship between the Re number of the oil-water mixture at the moment of pumping into the separation system, the ratio of the hole diameter of the corrugated plates to the width, the mounting angle of the corrugated plate sets in the separation system and the separation efficiency were both investigated experimentally, and the rheological properties of all fluids entering the system and leaving the system in a separated form were also measured. used in the relevant calculations. The viscosity, density and oil ratio of the first Processed oil-water mixture sample from Batman Batı Raman oil production was measured and indicated in Table 1.

$\rho=$ Density of oil-water mixture $\left(\mathrm{kg} / \mathrm{m}^{3}\right)$

$$
R e=\frac{\rho V D}{\mu}
$$

$\mathrm{V}=$ Pumping velocity of the mixture into the separation system $\mathrm{m}(/ \mathrm{s})$

$\mathrm{D}=$ Diameter of pipes used in the separation system $(25.4 \mathrm{~mm})$

$\mu=$ Viscosity of oil-water mixture (Pa.s)

Table 1: Properties of oil-water mixture

\begin{tabular}{|c|c|c|}
\hline Ratio of Oil in Water (\%) & Density (kg/m $\left.\mathbf{m}^{\mathbf{3}}\right)$ & Viscosity (Pa.s) \\
\hline 10 & 870 & $5.1 \times 10^{-3}$ \\
\hline
\end{tabular}

As seen in Figure 1, oil-water mixture samples; Its viscosity was measured using a temperaturecontrolled viscometer, while its density was measured with a calibrated hydrometer. After the oil sample to be used in the study was obtained and its rheological properties were determined, the relevant experiments were started.

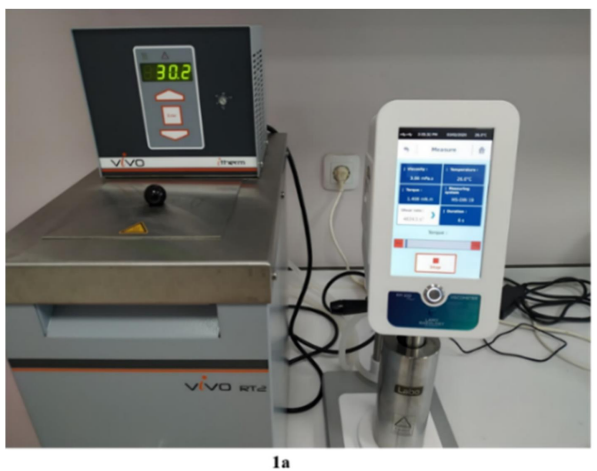

1a

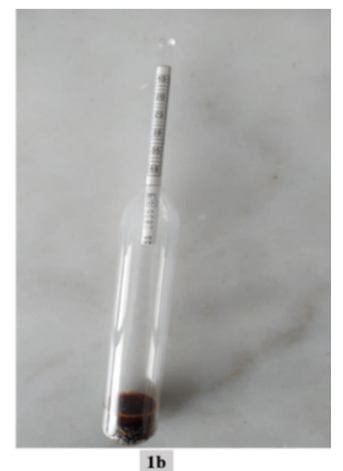

1b

Figure 1: 1a) Temperature Controlled Viscometer 1b) Handheld density meter

The separation system in which the experimental part of the separation process is carried out from the processes carried out within the scope of the study is shown in figure 2. The oil-water mixture is pumped to the separation system with the help of a pump, as can be seen in figure 2 . The flow (rate) of the mixture pumped into the system is adjusted by the cascade pump and the automation unit connected with the system, and the fluid is pumped into the system at the desired flow rates. The oil, which was brought into contact with the corrugated plates along the separation tank and separated during this time, accumulated as a layer (in the form of a film) on the mixture because its density was lower than the separated water. This oil layer, which accumulated on the surface of the separation tank, was also discharged to the separated oil storage tank by means of the separated oil discharge valve. Separation, which contains oil, albeit partially, and accumulates at the bottom of the separation tank; The separated water was removed 
from the separation tank with the discharge valve and the separated water was collected in the storage tank.

The separation system feeding tank used in the general experimental setup has a capacity of 2000 liters and is made of Polyethylene to be resistant to high temperatures and impacts. The separation system was mixed with a mixer for 30 minutes in the feed tank and the relevant temperature value of the mixture was achieved. Thanks to the mixing process, the oil-water mixture became homogeneous. It was aimed to pump a homogeneous mixture to the separation system during the experiment. The specified mixing time was also determined as a result of the preliminary experiments. In all relevant experiments, the temperature of the mixture was kept constant with the automation system installed in the same way and it was carried out at $26{ }^{\circ} \mathrm{C}$. The separated water and crude oil were discharged to the separated water and oil tanks through these discharge valves. The separated water storage tank has a capacity of 2000 liters and the separated oil storage tank has a capacity of 500 liters.

The properties of the corrugated plates used in the separation system are given in Table 2, and the separation was achieved through the sets established using the perforated corrugated plates with the specified properties, and all relevant experiments were carried out.

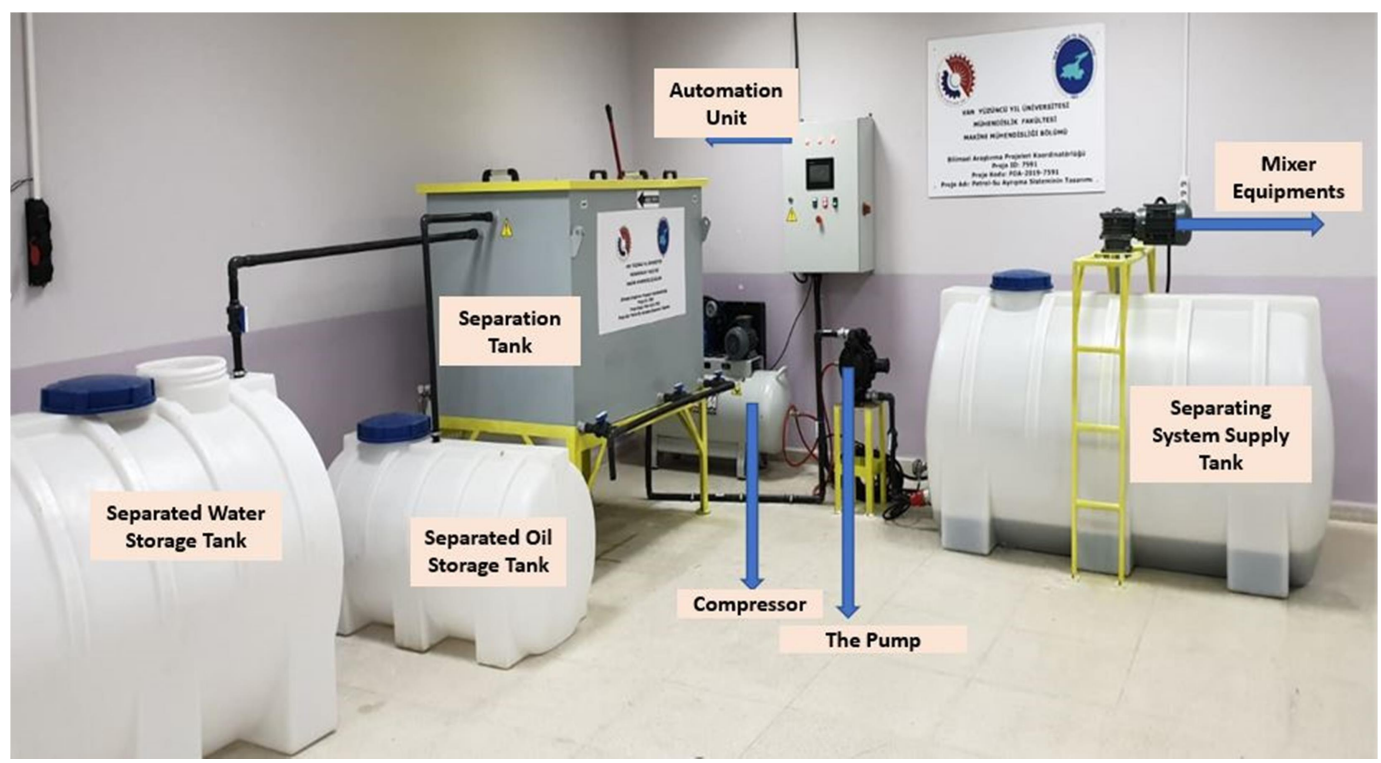

Figure 2: General state of the experimental setup

Table 2: Properties of the corrugated plates used in the experiments

\begin{tabular}{|l|l|}
\hline Corrugated Plate Length $(\mathrm{mm})$ & $800 \mathrm{~mm}$ \\
\hline Corrugated Plate Width $(\mathrm{mm})$ & $400 \mathrm{~mm}$ \\
\hline Distance Between Corrugated Plates $(\mathrm{mm})$ & $12 \mathrm{~mm}$ \\
\hline Corrugated Plate Hole Diameter $(\mathrm{mm})$ & $9,13,17 \mathrm{~mm}$ \\
\hline
\end{tabular}

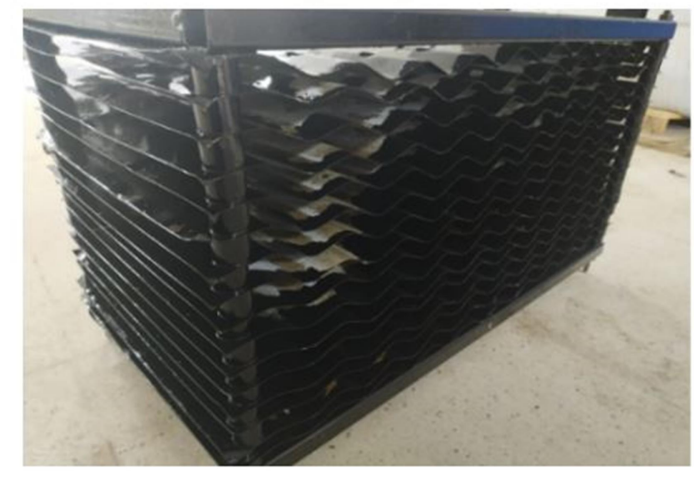

a

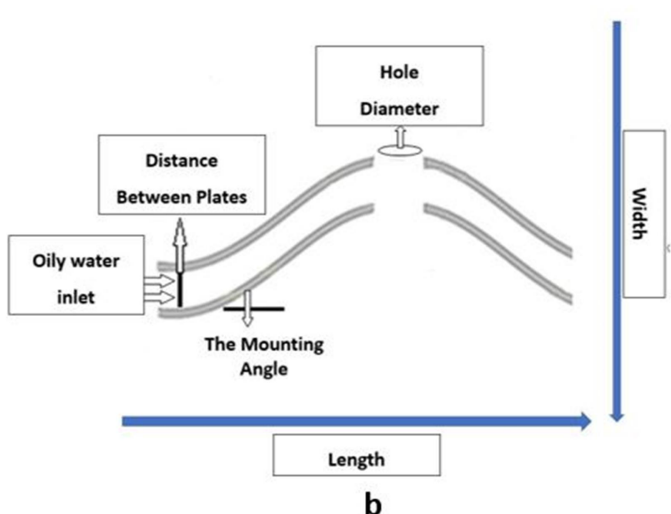

Figure 3: A set of corrugated plates a ) Used in the treatment system b) Corrugated plate geometry 
Oil-water mixture pumped into the separation system; Separation is provided by passing through sets consisting corrugated plates seen in figure 3. Oil droplets in the mixture passed through corrugated plates stick to each other and collect on the surface like a film strip. Since the density of crude oil is lower than the density of water, the separated water is collected at the bottom of the separation tank.

\subsection{Optimization}

The studies carried out in the optimization part of the related study are shown below step by step:

- In order to examine the levels of the parameters considered in the decomposition system and the effect of each parameter, the relevant parameters were optimized using the Box-Behnken Design interface of the Response Surface Method (RSM) (Trial Version). The Design Expert 7 (Trial Version) program was used for optimization and the lowest $(-1)$, center $(0)$ and highest $(+1)$ values of the selected parameters are shown in Table 3 . The experiment plan shown in Table 4 was carried out experimentally.

- As a result of this application, a total of 17 experiments were carried out. As can be seen in Table 4, a total of 17 experiments were proposed with the Box-Behnken Design and each proposed experiment was repeated twice to prove its accuracy and the average separation efficiency values were taken as basis. Analysis of variance (ANOVA) with Design-Expert 7.0 software (test version) was used to evaluate the statistical significance of the values and the effects of interaction between response and solution parameters. The accuracy of the quadratic model was evaluated using the coefficient of determination $\left(R^{2}\right)$ value.

Table 3: The Values and levels of the selected parameters

\begin{tabular}{|c|c|c|c|}
\hline Independent parameters & \multicolumn{3}{|c|}{ Levels } \\
\cline { 2 - 4 } & -1 & $\mathbf{0}$ & 6499.41 \\
\hline $\begin{array}{c}\text { A- Reynolds number of oil-water mixture (Re } \\
\text { Number) }\end{array}$ & 3033.06 & 4766.23 & 0.028 \\
\hline $\begin{array}{c}\text { B- Hole Diameter of Corrugated Plates / } \\
\text { Width of Corrugated Plates (d/w) }\end{array}$ & 0.015 & 0.021 & 50 \\
\hline $\begin{array}{c}\text { C-Mounting Angle of Corrugated Plates to } \\
\text { Separation System }(\boldsymbol{\alpha})\end{array}$ & 0 & 25 & $\mathbf{1}$ \\
\hline
\end{tabular}

In line with the experiments recommended by the optimization program, the density, viscosity and oilwater ratio of each sample at the relevant temperature value were measured and the test plan recommended by the RSM program is shown in Table 4. In terms of the reliability of the experimental results, all experiments were performed in duplicate.

Table 4: Experiments Plan

\begin{tabular}{|c|c|c|c|}
\hline Experiment No & $\mathbf{d} / \mathbf{w}$ & $\boldsymbol{\alpha}$ & Re Number \\
\hline $\mathbf{1}$ & 0.015 & 0.00 & 4766.23 \\
\hline $\mathbf{2}$ & 0.028 & 0.00 & 4766.23 \\
\hline $\mathbf{3}$ & 0.015 & 50.00 & 4766.23 \\
\hline $\mathbf{4}$ & 0.028 & 50.00 & 4766.23 \\
\hline $\mathbf{5}$ & 0.015 & 25.00 & 3033.06 \\
\hline $\mathbf{6}$ & 0.028 & 25.00 & 3033.06 \\
\hline $\mathbf{7}$ & 0.015 & 25.00 & 6499.41 \\
\hline $\mathbf{8}$ & 0.028 & 25.00 & 6499.41 \\
\hline $\mathbf{9}$ & 0.021 & 0.00 & 3033.06 \\
\hline $\mathbf{1 0}$ & 0.021 & 50.00 & 3033.06 \\
\hline $\mathbf{1 1}$ & 0.021 & 0.00 & 6499.41 \\
\hline $\mathbf{1 2}$ & 0.021 & 50.00 & 6499.41 \\
\hline $\mathbf{1 3}$ & 0.021 & 25.00 & 4766.23 \\
\hline $\mathbf{1 4}$ & 0.021 & 25.00 & 4766.23 \\
\hline $\mathbf{1 5}$ & 0.021 & 25.00 & 4766.23 \\
\hline $\mathbf{1 6}$ & 0.021 & 25.00 & 4766.23 \\
\hline $\mathbf{1 7}$ & 0.021 & 25.00 & 4766.23 \\
\hline
\end{tabular}


Transition from laminar to turbulent flow; geometry, surface roughness, flow rate, surface temperature, fluid type and many other parameters. The flow regime basically depends on the ratio of inertial forces to viscous forces in the fluid [19].

\section{Results and Discussion}

The designed oil-water separation system, 3 different oil samples were pumped at different flow rates using corrugated plates with different hole diameters. A series of studies were carried out for optimization processes by using the Box-Behnken interface through the Response Surface program in line with the parameters and levels used. Based on the trial designs determined by the optimization program, all relevant experiments were carried out in duplicate.

Table 6: Separation efficiency results of oil-water mixture samples

\begin{tabular}{|c|c|c|c|c|}
\hline Run & $\begin{array}{c}\text { Factor 1 } \\
\mathbf{d} / \mathbf{w}\end{array}$ & $\begin{array}{c}\text { Factor 2 } \\
\boldsymbol{\alpha}\end{array}$ & $\begin{array}{c}\text { Factor 3 } \\
\text { Re Number }\end{array}$ & $\begin{array}{c}\text { Response } \\
\text { Separation Efficiency }\end{array}$ \\
\hline $\mathbf{1}$ & 0.015 & 0.00 & 4766.23 & 97.50 \\
\hline $\mathbf{2}$ & 0.028 & 0.00 & 4766.23 & 97.42 \\
\hline $\mathbf{3}$ & 0.015 & 50.00 & 4766.23 & 97.79 \\
\hline $\mathbf{4}$ & 0.028 & 50.00 & 4766.23 & 97.71 \\
\hline $\mathbf{5}$ & 0.015 & 25.00 & 3033.06 & 97.68 \\
\hline $\mathbf{6}$ & 0.028 & 25.00 & 3033.06 & 97.63 \\
\hline $\mathbf{7}$ & 0.015 & 25.00 & 6499.41 & 97.72 \\
\hline $\mathbf{8}$ & 0.028 & 25.00 & 6499.41 & 97.43 \\
\hline $\mathbf{9}$ & 0.021 & 0.00 & 3033.06 & 97.74 \\
\hline $\mathbf{1 0}$ & 0.021 & 50.00 & 3033.06 & 97.46 \\
\hline $\mathbf{1 1}$ & 0.021 & 0.00 & 6499.41 & 97.77 \\
\hline $\mathbf{1 3}$ & 0.021 & 50.00 & 6499.41 & 99.25 \\
\hline $\mathbf{1 4}$ & 0.021 & 25.00 & 4766.23 & 99.25 \\
\hline $\mathbf{1 5}$ & 0.021 & 25.00 & 4766.23 & 99.23 \\
\hline $\mathbf{1 6}$ & 0.021 & 25.00 & 4766.23 & 99.25 \\
\hline $\mathbf{1 7}$ & 0.021 & 25.00 & 4766.23 & \\
\hline
\end{tabular}

In the experiments performed, the levels of the parameters and the separation efficiency values obtained for each sample are shown in Table 6.

Table 7: The ANOVA table of oil-water mixture

\begin{tabular}{|c|c|c|c|c|c|}
\hline Source & $\begin{array}{c}\text { Sum of } \\
\text { Squares }\end{array}$ & $\mathbf{d f}$ & Mean Square & F value & $\begin{array}{c}\text { p- value } \\
\text { Prob }>\text { f }\end{array}$ \\
\hline Model (significant) & 8.80 & 9 & 0.98 & 29.42 & $<0.0001$ \\
\hline $\mathbf{A}-\mathbf{d} / \mathbf{w}$ & 0.21 & 1 & 0.21 & 6.26 & 0.0409 \\
\hline $\mathbf{B - \alpha}$ & 0.67 & 1 & 0.67 & 20.07 & 0.0029 \\
\hline $\mathbf{C}-\mathbf{R e}$ Number & $2.000 \mathrm{E}-004$ & 1 & $2.000 \mathrm{E}-004$ & $6.016 \mathrm{E}-003$ & 0.9403 \\
\hline $\mathbf{A B}$ & 0.040 & 1 & 0.040 & 1.20 & 0.3090 \\
\hline $\mathbf{A C}$ & 0.093 & 1 & 0.093 & 2.80 & 0.1383 \\
\hline $\mathbf{B C}$ & 0.16 & 1 & 0.16 & 4.69 & 0.0670 \\
\hline $\mathbf{A}^{\mathbf{2}}$ & 2.41 & 1 & 2.41 & 72.58 & $<0.0001$ \\
\hline $\mathbf{B}^{\mathbf{2}}$ & 2.51 & 1 & 2.51 & 75.49 & $<0.0001$ \\
\hline $\mathbf{C}^{\mathbf{2}}$ & 1.92 & 1 & 1.92 & 57.63 & 0.0001 \\
\hline \multicolumn{7}{|l}{$\boldsymbol{R}^{\mathbf{2}}=\mathbf{0 . 9 7 4 2}$} \\
\hline
\end{tabular}

The ANOVA table obtained as a result of the considered parameters and the optimization process is shown in table 7 . In the optimization process, the $p$ value of each parameter and model equation should be less than 0.05 . As can be seen from the related table, each of the parameters handled independently and dependently affects the separation efficiency. In addition, it is seen that the most effective parameter on the separation efficiency is the mounting angle $(\alpha)$ of the corrugated plates in the separation system. At the same time, it is seen that the $\mathrm{R}^{2}$ value obtained is very close to $1(0.9742)$ and it is concluded that the model applied and the results obtained are compatible with each other by looking at this value. 
The relationship between the experimental data and the results of the model equation for the parameters considered within the scope of the study is shown in figure 7. It is seen that the experimental results obtained and the results predicted by the optimization program are very close to each other and the experimental results are clustered around the linear line. By looking at this clustering around the linear line, it is concluded that the measured separation efficiency values are correct.

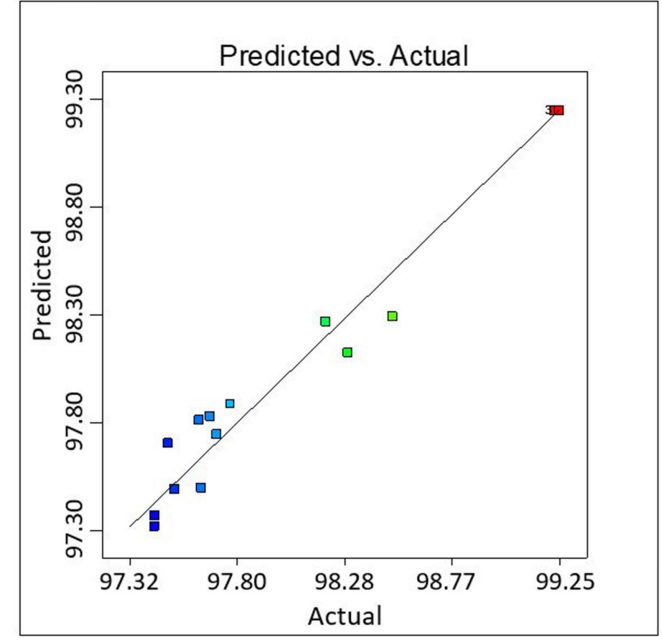

Figure 7: The plot of experimental vs. predicted responses for oily water mixture separation

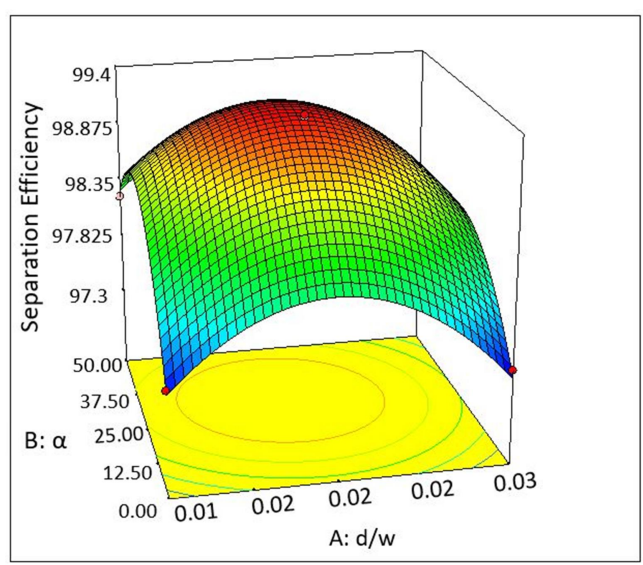

Figure 8: Response surface plots of oil-water mixture sample; effect of mounting angle of corrugated plates $(\alpha)$ and hole diameter of corrugated plates/corrugated plates width $(\mathrm{d} / \mathrm{w})$

The effect of the parameters of the mounting angle of the corrugated plates in the separation system and the ratio of the hole diameter of the corrugated plates to the plate width on the separation efficiency are shown in Figure 8. As the mounting angle of the plates to the separation system increases, separation efficiency increases up to 25-30 degrees, and separation efficiency decreases at higher angle values than the relevant angle values. As the angle value increases, the degree of inclination of the plates increases. With this increasing slope value, the flow rate of the mixture from the surface of the plates also increases. While increasing velocity value has a positive effect on separation efficiency up to a certain value, it has a negative effect on slope values above the optimum value. As the slope increases up to the optimum angle value, the dynamic pressure of the fluid in the separation tank increases and more deterioration occurs in the flow around the holes in the plates. Thanks to this deterioration in the flow, the oil droplets in the mixture become free more easily and stick to each other and rise to the surface [20]. When the effect of the $\mathrm{d} / \mathrm{w}$ parameter, which is considered within the scope of the separation process, on the separation efficiency is examined, it is seen that the $\mathrm{d} / \mathrm{w}$ value is optimum between $0.20-0.25$ values and the maximum separation efficiency is obtained in this range. In determining the optimum $\mathrm{d} / \mathrm{w}$ value in the separation process, the flow rate of the mixture in the separation tank and the ability of the oil droplets adhering to each other to come to the surface easily from the relevant holes are important. During the separation process, through the holes in the plates, both a deterioration in the flow and separation points are formed, and the oil droplets that stick to each other move upwards from the holes and accumulate on the surface. For this reason, if the $\mathrm{d} / \mathrm{w}$ value is low, there is a deterioration in the flow, but because the $\mathrm{d} / \mathrm{w}$ value is low, the oil droplets that stick together cannot rise to the surface. In the same way, if the $d / w$ value is high, the number of holes on the plate surface decreases and sufficient distortion cannot be created in the flow. For this reason, there are no separation points in the flow.

The effect of the mounting angle in the corrugated separation system and the Re number of the mixture pumped into the separation system on the separation efficiency is shown in figure 9. It is seen that the relevant parameters have an effect both on the separation efficiency and on each other. It is seen that the optimum Re number of the mixture should be in the range of 4500-4900 for maximum separation efficiency. As the Re number of the mixture increases, the type of flow changes from laminar to turbulent flow. separation processes using corrugated plates require the flow to be in the laminar-turbulent flow transition zone. The greater the turbulence of the flow, the harder it is for oil droplets to stick together. Because, at high Re number values, the turbulence in the flow is very high and the risk of the droplets adhering to each other to leave each other and become free again in the eddies formed in the regions 
where the flow separation takes place is high[2122]. The freed droplets are discharged together with the separated water and increase the oil rate in the separated water. In line with the optimum experimental plan obtained, the relevant experiment was carried out in duplicate and the separation efficiency value estimated by the optimization model was obtained. As the oil rises towards the surface, there is both vertical and horizontal flow movement in the separation tank due to the movement of oil droplets from the bottom of the separation tank to the surface [23]. Due to these flow movements, there is a decrease in the horizontal velocity of the mixture as one goes towards the surface of the tank

\section{Conclusions}

Within the scope of the related study, 3 different Re numbers of the oil-water mixture sample obtained from the crude oil production field, different $\mathrm{d} / \mathrm{w}$ values of the corrugated plates and 3 different mounting angle parameters to the separation system of the corrugated plates were taken into consideration and the effects of these parameters on the separation efficiency were investigated. Since there are 3 different parameters and each parameter has 3 different levels, optimization was made using RSM (Response Surface Method). The experiments recommended by the optimization program were carried out in duplicate and the effect of each parameter on the separation efficiency was examined dependently and independently. In addition, the optimum experimental setup recommended by the optimization program was set and the recommended relevant experiment was carried out and it was verified that the maximum separation efficiency was obtained. As a result, it has been observed that the separation efficiency value varies depending on the Re number of the fluid being pumped into the system, the $\mathrm{d} / \mathrm{w}$ value of the corrugated plates and also the mounting angle of the corrugated plates in the separation system. The separation efficiency varies due to flow characteristics and the ability of the mixture to interact with thecorrugated plates. The optimum connection between the separation efficiency and the parameters discussed was determined, and accordingly, the maximum separation efficiency value was determined experimentally.

\section{Acknowledgement}

The authors acknowledge the financial support of The Scientific and Technological Research Council of Turkey (TUBITAK) for funding under project No: $120 \mathrm{M} 786$ and the Scientific Research Projects Coordinator of Van Yüzüncü Y1l University with project numbered FOA-2019-7591.

\section{References}

[1] Halliburton: Water management [online]. (2006) http://www.halliburton.com.

[2] James, P., Rainer, EF.: Produced water: technological/environmental issue and solutions. In Environmental Science Research, vol 616, (1993).

[3] Khatib, Z., Verbeek, P.: Water to value produced water management for sustainable field development of mature and green fields, J. Petrol Technol., Jan, (2003) pp. 26-28.

[4] Razi, FA., Alireza, P., Zainal, AZ., Chuah AL., Awang, BDA., Siavash, MS.: Application of membrane-coupled sequencing batch reactor for oilfield produced water recycle and beneficial reuse. Bio Resource Technology, vol 101, no. 18: (2010) pp. 6942-6949.

[5] Razi, FA., Pendashteh, A., Abdullah, LC., Biak, DRA., Madaeni, SS., Abidin, ZZ.: Review of technologies for oil and gas produced water treatment. Journal of Hazardous Materials, vol 170, no.2-3: (2009), pp. 530-551. 
[6] Hashim, R, Abdolhamid, A., Mars, E.: Evaluation of bio-surfactants enhancement on bioremediation process efficiency for crude oil contaminated soil at oilfield. Strategic Study, vol 20, (2009) pp. 2530.

[7] John, A., Veil, Markus G., Puder, Elcock D., Robert J., Redweik, J.: A white paper describing produced water from production of crude oil. Natural Gas and Coal Bed Methane produced water, (2004) P0401pdf.

[8] Zhaohui, X., Ashok, M., Wilfred, C. (2003). Detection of Benzene, Toluene, Ethylbenzene, and Xylenes (BTEX) Using Toluene Dioxygenase-Peroxidase Coupling Reactions. Biotechnology Progress, 19(6), pp. 1812-1815.

[9] Agency USEP.: National center for environmental assessment-washington office of research and development. Carcinogenic Effects of Benzene: An Update, Washington DC., (2004) pp. 57.

[10] Reusser, DE., Field, JA.: Determination of benzyl succinic acid in gasoline-contaminated ground water by solid-phase extraction coupled with gas chromatography. Mass Spectrometry, vol 953, (2004) pp. 215-225.

[11] Gu, Y.: Separation of produced petroleum fluids using a coalescer column. Research Proposal Submitted to Petroleum Technology Research Centre (PTRC), (2001).

[12] Rao, TC., Patil, DP.: Developments in gravity separation, J. Mines Metals \&Fuels, vol 46, no. 383: (1998).

[13] Ruiz, MC., Padilla, R.: Separation of liquid-liquid dispersion in a deep-layer American chemical society gravity settler, Part II Mathematical Modeling of the Settler, Hydrometallurgy, vol 42, no. 281 (1998.)

[14] Kenawy, FA., Kandil, ME., Aboarab, TW.: Produced water treatment technology-a study of oil/water separation in gravity-type cross flow pack separators for qualitative separation, SPE Prod. \& F acil, vol 12, no. 112 (1997).

[15] Morrison, J.: Tilted plate separators for refinery wastewater, Oil and Gas Journal, vol 68, no. 50: (1970) pp. 80-86.

[16] Kok, DF., Marson, HW.: Tanker ballast water meets through treating specs, Oil and Gas Journal, vol 76, no. 49: (1978) pp. 7-92.

[17] Oruç, M., Yayla S.: Experimental investigation of oil-in water separation using corrugated plates and optimization of separation system. Separation Science and Technology, (2021), DOI: 10.1080/01496395.2021.1939377

[18] Mohr, K. S.: A new type of high efficiency oil-water separator for better water quality management, Submitted to the faculty of the graduate college of the Oklahoma State University in partial fulfillment of the requirements for the degree of Master of Science. December 1993.

[19] Algifri, AH., Bhardwaj, RK., Rao, YVN.: Turbulence measurements in decaying swirl flow in a pipe. Applied Scientific Research, vol 45, (1988) pp. 233-250.

[20] Escobar, OM.: The graduate school performance evaluation of modified liquid-liquid cylindrical cyclone. Petroleum Engineering the Graduate School the University of Tulsa, (2005).

[21] Guerin, TF.: Heavy equipment maintenance wastes and environmental management in the mining industry. J. Environ. Manage, vol 66, (2002) pp. 185-199.

[22] Yayla, S., Olcay, A.B., Ibrahim, S.S.: Numerical investigation of coalescing plate system to understand the separation of water and oil in water treatment plant of petroleum industry, Engineering Applications of Computational Fluid Mechanics, vol 11, no. 1, (2017) pp. 184-192.

[23] Perry JH, Perry RH, Chilton CH, Kirkpatrick SD.: Chemical engineers handbook (4 ed)., McGrawHill Book Company, (1997), New York, NY. 